\title{
Effect of Carbon Nanotubes Addition on the Mechanical and Thermal Properties of Epoxy Matrices
}

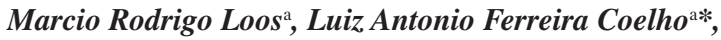 \\ Sérgio Henrique Pezzin ${ }^{\mathrm{a}}$, Sandro Campos Amico ${ }^{\mathrm{b}}$ \\ ${ }^{a}$ Centro de Ciências Tecnológicas - UDESC, \\ Campus Universitário Prof. Avelino Marcante, s/n, Bom Retiro, 89223-100 Joinville - SC, Brazil \\ ${ }^{\mathrm{b}}$ Laboratório de Polímeros - LAPOL, Departamento de Materiais - DEMAT, \\ Programa de Pós-Graduação em Engenharia de Minas, Metalúrgica e de Materiais - PPGEM, \\ Universidade Federal do Rio Grande do Sul, \\ 91501-970 Porto Alegre - RS, Brazil
}

Received: December 17, 2007; Revised: May 16, 2008

\begin{abstract}
In this work, nanocomposites were prepared by adding a small amount of single walled carbon nanotubes (SWCNTs) to an epoxy resin aiming to study the resulting mechanical, viscoelastic and thermal properties of the nanocomposites. To optimize the processing of the nanocomposites and to favor a homogeneous dispersion of the SWCNTs on the matrix, acetone was used to reduce resin viscosity, increasing diffusion of the SWCNTs in the solution. The epoxy/SWCNTs/acetone systems were also sonicated in order to minimize entanglement of the SWCNTs. The systems were characterized by Fourier transform infrared spectroscopy, Raman spectroscopy, thermogravimetry, differential scanning calorimetry and dynamic mechanical analysis. The results indicated that the addition of small amounts of SWCNTs to epoxy leads to slight structural changes in the epoxy matrix which, together with the presence of SWCNTs, may reflect on its mechanical and viscoelastic properties
\end{abstract}

Keywords: carbon nanotubes, epoxy matrix, nanocomposites, mechanical properties

\section{Introduction}

Carbon nanotubes (CNTs) display a wide range of unique mechanical, optical, and electrical properties along with chemical stability. Their mechanical properties (especially tensile strength) considerably exceed those of currently available fiber materials ${ }^{1}$.

Recent research articles have reported the use of nanotubes in polymer $^{2}$, metal $^{3}$ and ceramic ${ }^{4}$ matrix composites. In the polymer field, epoxy resin is one of the most often used polymer matrix for advanced composite applications. The group of resins of this family presents good stiffness and specific strength, dimensional stability, chemical resistance, and also strong adhesion to the embedded reinforcement ${ }^{5}$. The preparation of CNT-reinforced epoxies and any other kind of polymer, however, requires a homogeneous dispersion and a strong interfacial interaction between the nanotubes and the polymer.

The addition of solvents to thermoset resins is a possible route to decrease resin viscosity, allowing better distribution of nanofillers since the solvent decreases the viscosity of the solution and consequently the SWCNTS may diffuse faster ${ }^{6-8}$. In fact, the use of a solvent is considered an alternative to adequately prepare nanocomposites using CNTs as fillers in epoxy matrices ${ }^{9-11}$, being a necessary step due to the high viscosity of the neat epoxy which makes the dispersion of these finely divided materials very challenging.

The main purpose of this study is to obtain randomly oriented single-walled carbon nanotubes (SWCNTs)/epoxy nanocomposites using a minimum amount of solvent, following a tip sonication and casting molding route, and to analyze the chemical, thermal and mechanical properties of the produced nanocomposites.

\section{Experimental}

\subsection{Materials}

The polymer matrix consisted of bisphenol-A-based epoxy resin (Araldite GY 251) with an amine-based hardener (Aradur HY 956), obtained from Huntsman Advanced Materials and Acetone (Quimidrol, $99.5 \%$ purity) was the chosen solvent. Single-walled carbon nanotubes grown by arc discharge were supplied by Federal University of Minas Gerais (UFMG, Brazil) and its purity was higher than 95\% (supplier data sheet).

For the preparation of the samples, SWCNTs $(0.10$ or $0.25 \%$ $\mathrm{W} . \mathrm{w}^{-1}$ in relation to the epoxy matrix) were dispersed in acetone using simultaneous magnetic stirring $(100 \mathrm{rpm})$ and sonication (Sonics Vibration, $500 \mathrm{~W}$ and $20 \mathrm{kHz}$ ). The amount of acetone used, $10 \%$ w. $\mathrm{w}^{-1}$ in relation to the epoxy matrix, was chosen in order to minimize viscosity and yet avoiding the use of a large amount of solvent, as published earlier ${ }^{12}$.

The mixture was heated to $50{ }^{\circ} \mathrm{C}$ under vacuum $\left(\approx 10^{-2} \mathrm{~atm}\right)$ for an hour to remove most of the solvent. The epoxy was then added, and the mixture sonicated under magnetic stirring $(100 \mathrm{rpm})$ for one hour. Further, the system was stirred (100 rpm) under vacuum at $70{ }^{\circ} \mathrm{C}$ for 60 minutes. To evaluate the removal of all solvent, the samples were weighed before the addition of acetone and before curing. Nevertheless, acetone traces could still be found in the nanocomposites. Then, the dispersions were left under vacuum for 4 more hours without heating. Later, the hardener was added $\left(5: 1 \mathrm{w}^{-\mathrm{w}^{-1}}\right)$ and the mixture was allowed to cure at $38^{\circ} \mathrm{C}$ for 30 hours. Neat epoxy resin samples were also prepared following the same route for comparison.

\subsection{Sample characterization}

The carbon nanotubes (CNTs) employed in this work were produced by arc discharge using nanoparticles of $\mathrm{Co} / \mathrm{Ni}$ as catalyst. A TEM image of CNTs after purification is presented in Figure 1.

The degree of purity observed in the TEM micrograph is confirmed by Raman spectroscopy, shown in Figure 2. The peak related to the amorphous carbon may be found at $1350 \mathrm{~cm}^{-1}$ (D band) and the one representing the CNTs at $1580 \mathrm{~cm}^{-1}$ ( $\mathrm{G}$ band). The low intensity 
of the D band in comparison with the $\mathrm{G}$ band is a strong indicative of low structural disorder in the SWCNTs.

The characterization of the solutions and the composites included the following analysis:

- TEM: Transmission electron microscopy (TEM) analyses were carried out in a JEOL - JEM 1200ExII $(120 \mathrm{kV})$ equipment in samples previously obtained with an ultra-microtome.

- Raman: The Raman spectrum of the samples was obtained by using the 514-nm line of an argon laser (power density of $1 \mathrm{~mW}$ ) and a triple-grating spectrometer (Jobin-Ivon).

- Viscosity: Viscosity measurements were performed using a Brookfield CAP 2000 viscosimeter at $50{ }^{\circ} \mathrm{C}$ with $2.5 \mathrm{~mm}$ diameter cone-plate geometry, the cone having an inclination of 0.1 radians. These measurements were carried out on the solutions before the removal of acetone.

- Thermal Analyses: Thermogravimetry (TG) was conducted in a Netzsch (STA 449C) equipment, heating the samples from 15 to $900{ }^{\circ} \mathrm{C}$ at a heating rate of $10{ }^{\circ} \mathrm{C} / \mathrm{min}$ under nitrogen atmosphere. Differential scanning calorimetry (DSC) analyses were carried out in a TA 2010 thermal analyzer under nitrogen atmosphere at $10{ }^{\circ} \mathrm{C} / \mathrm{min}$, from -50 to $250{ }^{\circ} \mathrm{C}$.

- FTIR Analysis: Fourier transform infrared spectroscopy (FTIR) analyses were conducted in a Perkin-Elmer Spectrum One B

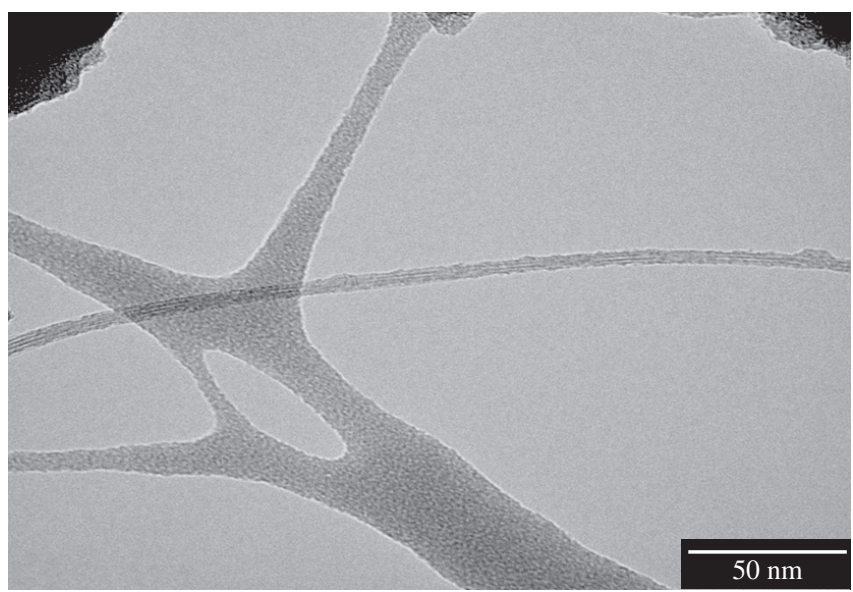

Figure 1. TEM image of SWCNTs.

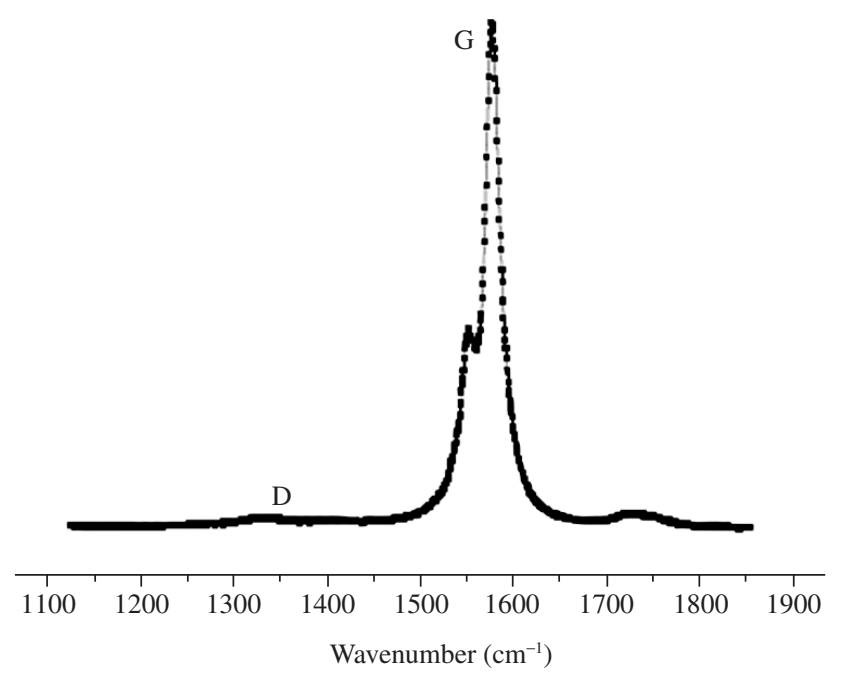

Figure 2. Raman spectroscopy of SWCNTs (provided by the supplier). equipment with a resolution of $4 \mathrm{~cm}^{-1}$, from 4000 to $650 \mathrm{~cm}^{-1}$, on transmission mode.

- Mechanical Tests: Tensile, compressive and flexural tests were performed in a Universal Testing Machine EMIC DL 3000. Tensile tests used a $500 \mathrm{kgf}$ load-cell and a $5 \mathrm{~mm} / \mathrm{min}$ crosshead speed, according to ASTM D638. Compressive tests used a load cell of $2000 \mathrm{kgf}$ and a traveling speed of $1.3 \mathrm{~mm} / \mathrm{min}$ (ASTM D 695-02a). Three-point bending (flexural) tests used a load cell of $2000 \mathrm{kgf}$ and a traveling speed of $2.6 \mathrm{~mm} / \mathrm{min}$ (ASTM D 79002). Izod impact tests were carried out in a CEAST equipment (model 6545), using a $1 \mathrm{~J}$ hammer, according to ISO 180/A.

- Dynamic Mechanical Analysis: Dynamic mechanical analyses were performed in a TA Instruments 2980 equipment, operating in three-point bending (flexural) mode, dual-cantilever clamp, at an oscillation frequency of $1 \mathrm{~Hz}$. Data were collected from -50 to $170{ }^{\circ} \mathrm{C}$ at a scanning rate of $10{ }^{\circ} \mathrm{C} / \mathrm{min}$.

- Morphological Characterization: - SEM: Morphological characterization of the fractured surface of the samples was carried out via scanning electron microscopy - SEM (Zeiss DSM $940 \mathrm{~A}$ at $15 \mathrm{kV}$ ).

\section{Results and Discussion}

\subsection{Viscosity}

Figure 3 presents the viscosity of the solution (10\% w.w ${ }^{-1}$ acetone) of epoxy, with and without SWCNT, as a function of shear rate. An increase of $8-12 \%$ in viscosity for the $0.10 \%$ w.w ${ }^{-1}$ of SWCNTs, in comparison with the unreinforced resin was observed. However, the addition of $0.25 \% \mathrm{w} . \mathrm{w}^{-1}$ of SWCNTs surprisingly decreased viscosity. It is important to also take into consideration the effect of the solvent on the viscosity. In a recent $\operatorname{study}^{12}$, the authors have showed that the addition of acetone decreases, in up to $50 \%$, the viscosity of the epoxy resin, what is expected considering that the solvating effect of the solvent weakens inter-chain interactions ${ }^{10}$.

Furthermore, Cotiuga et al. ${ }^{14}$ found that increasing the duration of ultrasonic irradiation of the CNTs dispersions, an initial increase in solution viscosity was obtained, suggesting this to be an indication of the progress of the SWCNTs exfoliation. For long sonication periods, however, the viscosity started decreasing, which was interpreted as a

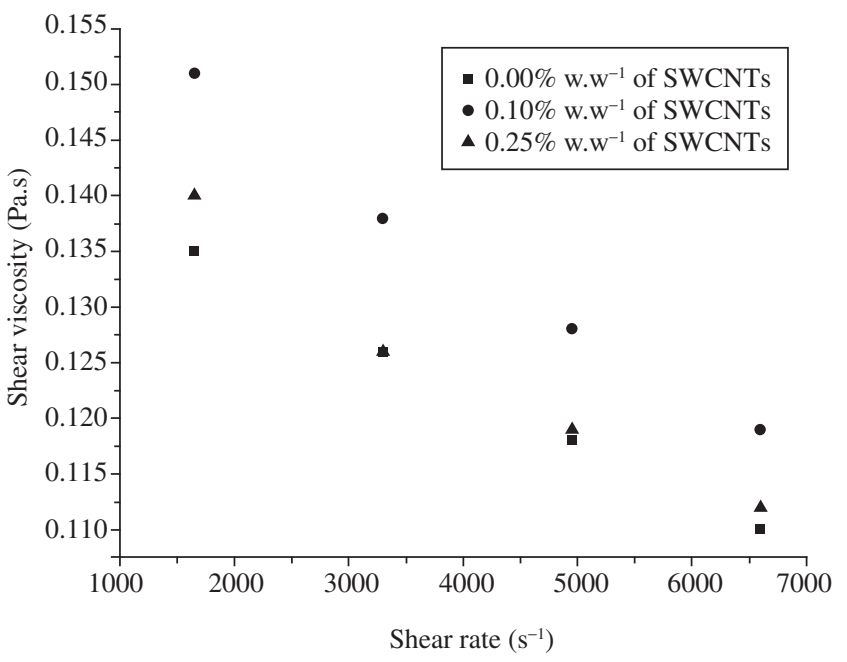

Figure 3. Viscosity of the $0.00,0.10$ and $0.25 \% \mathrm{w}^{-\mathrm{w}^{-1}}$ of SWCNTs samples under different shear rates. 
consequence of breakage/damage (with a possible decrease in average length) of the SWCNTs.

It is difficult to give a detailed account of the mechanisms leading to a lower viscosity. Nevertheless, the increase in viscosity with the addition of $0.1 \%$ w. $\mathrm{W}^{-1}$ of SWCNTs could happen due to suppressed vortices in the presence of nanotubes ${ }^{15}$. On the other hand, a higher amount of SWCNTs could favor the contact between the epoxy molecules and the nanotubes, causing some orientation of those molecules and, consequently, a reduction in viscosity; besides, the release of trapped solvent traces could also lead to a reduction in viscosity.

\subsection{Infrared spectroscopy}

Figure 4 shows the FTIR spectra of the neat epoxy and epoxy/ SWCNT dispersions before curing. It is observed that the absorption bands are quite similar, indicating that neither acetone nor SWCNTs appear to change the chemical structure of the epoxy, similar to what has been suggested by $\mathrm{Lau}^{9}$. Therefore, the analysis focused on the FTIR spectra of the cured samples with different carbon nanotubes concentrations, where the influence of the SWCNTs (and acetone) in the curing cycle of the epoxy resin.

Absorption bands of epoxy resins in the region of $800-920 \mathrm{~cm}^{-1}$ are commonly used for the determination of epoxide groups ${ }^{12,18,26}$. The changes in some absorption bands during cure can be easily observed ${ }^{18}$. In this procedure, absorption bands in the range $910-920 \mathrm{~cm}^{-1}$ range (using the band near $830 \mathrm{~cm}^{-1}$ as an internal standard, assigned to the aromatic ring bending out of plane $^{9}$ ) in the FTIR spectrum of epoxide resins are used for the determination of epoxide groups ${ }^{26}$. The absorption intensity of this band (910-920 $\left.\mathrm{cm}^{-1}\right)$ is considered maximum for uncured epoxy resins, decreasing with the conversion of the epoxide groups during the curing cycle, when the conversion of the epoxide groups takes place ${ }^{12,18}$. Figure 5 shows the FTIR spectra of the neat cured (and uncured) epoxy and the cured nanocomposites. The band corresponding to the epoxide groups $\left(910-920 \mathrm{~cm}^{-1}\right)$ can be clearly identified. Comparing the spectra of the cured and uncured resin, it can be seen that the intensity of the reference band is quite the same to the cured epoxy and nanocomposites, which means that the presence of the CNTs (and the acetone) have not showed influence in the extension of the conversion of the epoxide groups, providing a extensive curing cycle.

Significant changes in the infrared absorption bands could not be easily observed and there is no evidence of any pi-pi interactions.

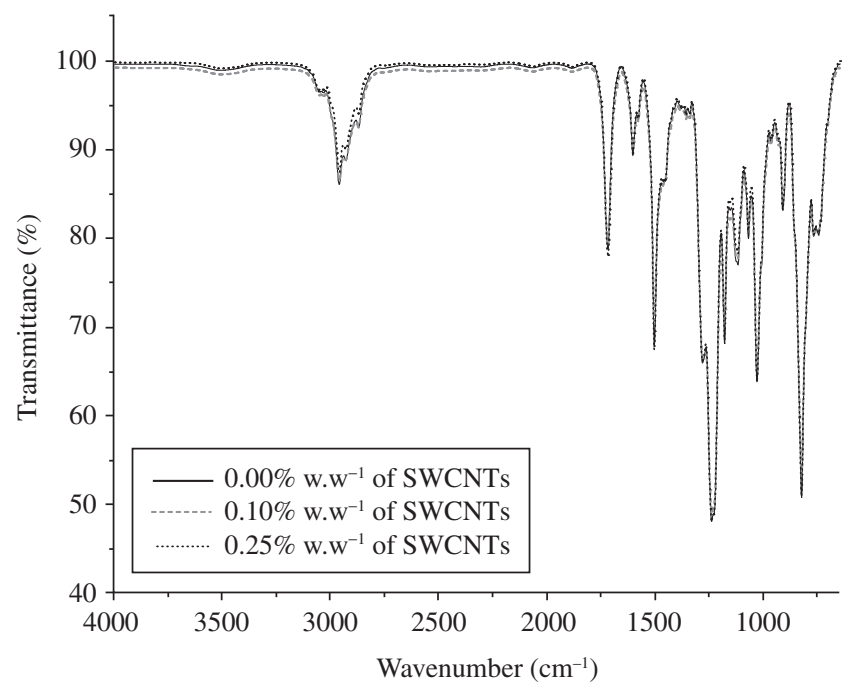

Figure 4. FTIR spectra obtained for uncured epoxy samples with 0.00, 0.10, and $0.25 \% \mathrm{w} . \mathrm{W}^{-1}$ of SWCNTs.
Indeed, there appears to be no literature reports on this type of interactions in DGEBA/carbon nanotube systems. Besides, spectral changes that could be related to hydrophobic interactions between DGEBA and SWNTs were not seen.

\subsection{Thermogravimetry}

In the TGA, all samples started losing weight around $70{ }^{\circ} \mathrm{C}$, with a $90 \%$ degradation around $550{ }^{\circ} \mathrm{C}$. There is an initial small weight loss between $70-190{ }^{\circ} \mathrm{C}$, possibly corresponding to the evaporation of trapped solvent, a similar behavior to that reported by $\mathrm{Lau}^{17}$. The second weight loss, between $190-320{ }^{\circ} \mathrm{C}$ (peak at $250{ }^{\circ} \mathrm{C}$ ), is possibly due to the decomposition of lower molecular weight material, and the third one, between $290-490{ }^{\circ} \mathrm{C}$ (peak at $370{ }^{\circ} \mathrm{C}$ ), refers to the degradation of the SWCNT/epoxy nanocomposites ${ }^{11}$.

Generally, thermoset polymers with higher cross-link density show higher maximum decomposition temperature. The cross-link density is maximized when the complete stoichiometric conversion of epoxy is achieved. With the addition of acetone (and SWCNTs), as discussed by Hong ${ }^{18}$, cross-link density may be reduced, resulting in slightly lower decomposition temperatures.

\subsection{Mechanical properties}

The results of all mechanical testing carried out are summarized in Table 1. Regarding tensile properties, there is an increasing trend in strength (up to 8\%) and Young's modulus (up to 7\%) for the nanocomposites.

Allaoui et al. ${ }^{19}$ studied the mechanical properties of nanocomposites of multiwalled carbon nanotubes (MWCNTs)/epoxy showing elastomeric behavior due to the incomplete curing of the epoxy. In

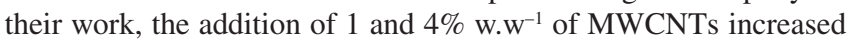
the Young's modulus in 100 and $200 \%$, respectively. Varying the curing cycle, Loos et al. ${ }^{20}$ found a similar behavior for SWCNTs/ epoxy systems, achieving an increase of up to $495 \%$ in the Young's Modulus when $0.25 \%$ w. $\mathrm{w}^{-1}$ of SWCNTs was added to partially cured epoxy systems.

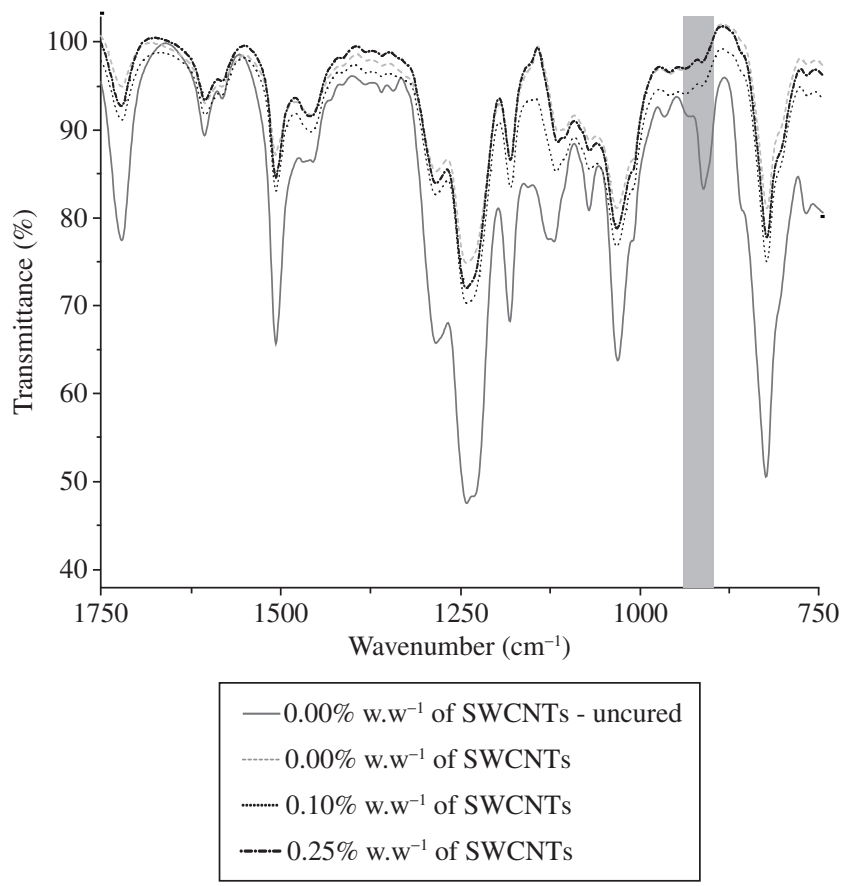

Figure 5. FTIR spectra obtained for cured epoxy samples with $0.00,0.10$, $0.25 \%$ w. $w^{-1}$ of SWCNTs. 
Table 1. Tensile, compressive, flexural and impact properties of CNT/epoxy composites.

\begin{tabular}{|c|c|c|c|}
\hline & \multicolumn{3}{|c|}{ SWCNTs $\left(w \cdot w^{-1}\right)$} \\
\hline & $0.00 \%$ & $0.10 \%$ & $0.25 \%$ \\
\hline \multicolumn{4}{|l|}{ Tensile properties } \\
\hline Young's modulus (GPa) & $2.4 \pm 0.3$ & $2.5 \pm 0.2$ & $2.6 \pm 0.2$ \\
\hline Elongation at break (\%) & $3.0 \pm 0.2$ & $3.0 \pm 0.4$ & $3.0 \pm 0.4$ \\
\hline Strength $(\mathrm{MPa})$ & $42.1 \pm 1.3$ & $45.5 \pm 2.6$ & $45.1 \pm 3.5$ \\
\hline \multicolumn{4}{|l|}{ Compressive properties } \\
\hline Strength $(\mathrm{MPa})$ & $57.8 \pm 2.5$ & $60.7 \pm 5.0$ & $59.4 \pm 4.5$ \\
\hline Modulus (GPa) & $1.2 \pm 0.1$ & $1.3 \pm 0.1$ & $1.3 \pm 0.1$ \\
\hline \multicolumn{4}{|l|}{ Flexural properties } \\
\hline Strength (MPa) & $76.8 \pm 3.3$ & $76.2 \pm 3.1$ & $80.1 \pm 4.6$ \\
\hline Modulus (GPa) & $3.0 \pm 0.2$ & $2.9 \pm 0.2$ & $3.0 \pm 0.2$ \\
\hline \multicolumn{4}{|l|}{ Impact properties } \\
\hline Izod strength $\left(\mathrm{kJ} / \mathrm{m}^{2}\right)$ & $2.2 \pm 0.2$ & $1.6 \pm 0.2$ & $1.6 \pm 0.1$ \\
\hline
\end{tabular}

On the other hand, $\mathrm{Ci}$ et al..$^{21}$ evaluated the mechanical properties of SWCNTs/epoxy nanocomposites with different rigidity degrees and observed that the Young's Modulus of the epoxy resins with high stiffness (2.44 GPa) were not significantly altered with the addition of carbon nanotubes, i.e. it appears that when the epoxy is adequately cured, the gain in rigidity with the addition of SWCNTs is much lower.

Regarding compression tests, the compression strength of the pure epoxy was $57.8 \mathrm{MPa}$, whereas the nanocomposites presented slightly ( $8 \%$ ) higher mean values (see Table 1$)$. In addition, compression modulus followed the same trend. Using a much higher amount and a different kind of CNT (MWCNTs - 5\% w.w ${ }^{-1}$ ), Schadler et al..$^{22}$ obtained an increase from 3.6 to $4.5 \mathrm{GPa}(24 \%)$ in the compression modulus of MWCNTs/epoxy. According to this author, for MWCNT/ epoxy composites, the compression modulus is higher than the tensile modulus, indicating that load transfer to the nanotubes is higher when all the layers are involved, whereas in tensile tests only the external layers are required. This effect was not observed in this work, which studied SWCNT/epoxy composites, and the tensile modulus was two-fold that of the compression modulus.

Virtually no changes were found for the flexural properties of the studied nanocomposites (Table 1). In this respect, contrasting reports may be found in the literature. Moniruzzaman et al. ${ }^{23}$ obtained an increase of 15 and $8 \%$ in flexural modulus and strength, respectively, for SWCNT/epoxy nanocomposites with $0.5 \%$ w. $\mathrm{w}^{-1}$. On the other hand, $\mathrm{Lau}^{24}$ found a decrease of $10 \%$ in flexural strength of MWCNT/ epoxy nanocomposites using $2 \% \mathrm{~W} . \mathrm{w}^{-1}$. SEM revealed that nanotubes were easily pulled out from the samples during flexural testing due to the poor bonding between MWCNTs and epoxy.

The Izod impact test results are also included in Table 1 . The addition of SWCNTs decreased the impact strength of epoxy in $27 \%$. Miyagawa et al. ${ }^{25}$ also found a decrease in impact strength for epoxy matrix nanocomposites with fluorinated SWCNTs and suggested that it was due to a large addition of nanoinclusions after the epoxy had become excessively viscous. The decrease in impact strength also suggests poor interaction between the SWCNTs and the epoxy, where little or no energy dissipation phenomena at the interface appear to happen. The presence of acetone traces may also be adversely affecting impact strength.

A SEM image of the surface of a tensile fractured $0.25 \% \mathrm{w} . \mathrm{w}^{-1}$ of SWCNTs sample is presented in Figure $6 \mathrm{a}$, and $6 \mathrm{~b}$ shows a corresponding TEM micrograph. The SEM micrograph shows a typical brittle failure of highly cross-linked epoxy matrices, but some small

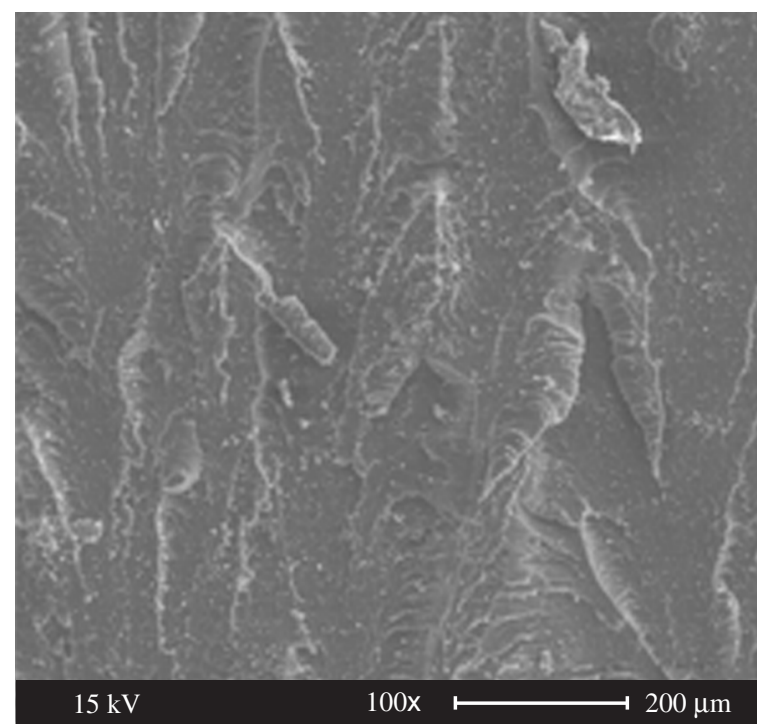

(a)

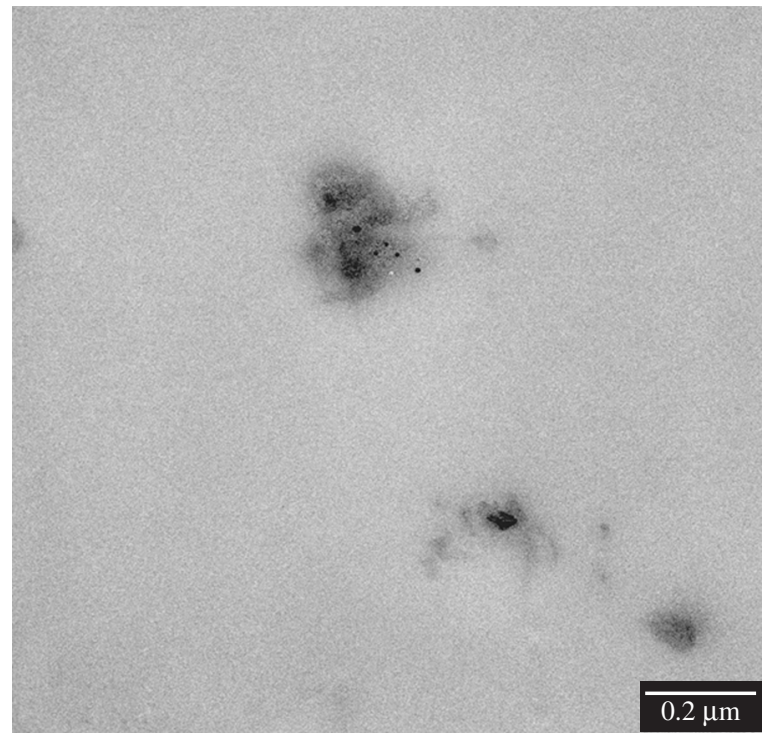

(b)

Figure 6. a) SEM micrograph of a CNT/epoxy composite fracture surface; and b) TEM of a CNT/epoxy nanocomposite surface. 
brighter points suggest the presence of agglomerates. This was confirmed by the qualitative investigation by TEM, which revealed the presence of some relatively large CNT agglomerates (ca. $200 \mathrm{~nm}$ ).

\subsection{Dynamical mechanical analysis}

Figure 7 a shows the storage modulus as a function of the temperature for the various epoxy systems. The presence of CNT influences the storage modulus of the epoxy resin in the glassy region and in the vicinity of its glass transition temperature (near $76^{\circ} \mathrm{C}$ ). The addition of 0.10 and $0.25 \%$ w.w $\mathrm{w}^{-1}$ of SWCNTs yielded a 9 and $16 \%$ increase in storage modulus, respectively, at $30^{\circ} \mathrm{C}$. This behavior can be explained in terms of possible physical interactions between the SWCNTs and the epoxy through their enormous interfacial area. Alternatively, this could simply be an increase in rigidity caused by the presence of a more rigid phase dispersed within the less rigid matrix phase.

The $\tan \delta$ curves of the neat epoxy and its nanocomposites are shown in Figure 7b. Although there was no significant variation in peak height, the glass transition temperature $\left(\mathrm{T}_{\mathrm{g}}\right)$, determined from the peak position in $\tan \delta$, showed a slightly clearer trend, increasing with the addition of SWCNTs (Table 2). The $\mathrm{T}_{\mathrm{g}}$ increases from $76^{\circ} \mathrm{C}$ in the neat epoxy to around $80^{\circ} \mathrm{C}$ in the nanocomposites. This small increase

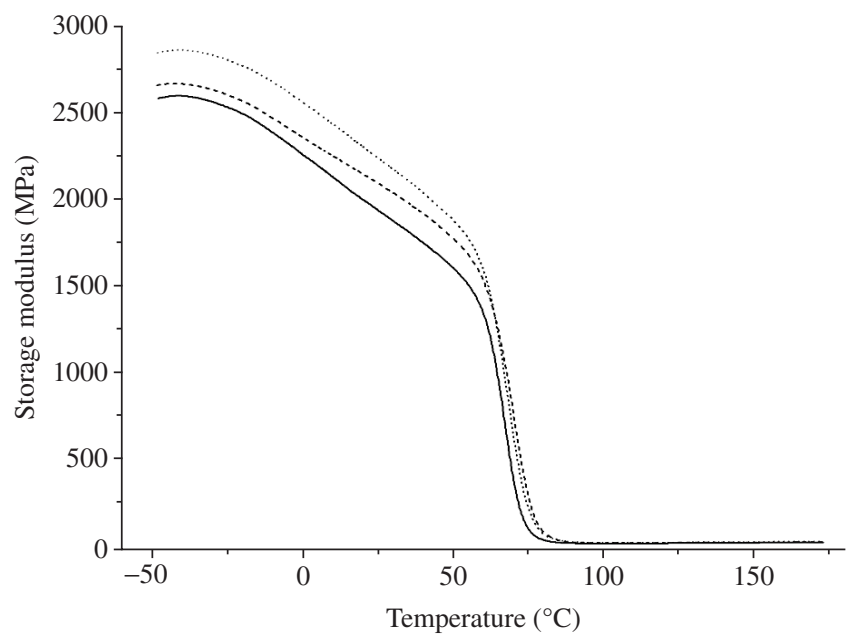

(a) could be interpreted as a reduction of the mobility of the epoxy around the carbon nanotubes due to their presence in the resin.

For comparison, Table 2 also shows the $\mathrm{T}_{\mathrm{g}}$ as estimated by DSC and loss modulus results, and although the values are somewhat different, they also appear to reveal a trend for a $\mathrm{T}_{\mathrm{g}}$ increase when SWCNTs are added to the epoxy matrix.

\section{Conclusions}

This work evaluated the effects caused by the addition of nanofillers, i.e. single walled carbon nanotubes (SWCNTs), on an epoxy resin

Table 2. Glass transition temperatures, $\mathrm{T}_{\mathrm{g}}\left({ }^{\circ} \mathrm{C}\right)$, obtained from DSC and DMA results.

\begin{tabular}{lccc}
\hline \multicolumn{1}{c}{ Sample } & DSC & $\begin{array}{c}\text { Loss } \\
\text { modulus }\end{array}$ & Tan $\delta$ \\
\hline Neat epoxy & 63 & 68 & 76 \\
$0.10 \% \mathrm{w}^{-1}$ of SWCNTs & 65 & 71 & 80 \\
$0.25 \% \mathrm{w}^{-1}$ of SWCNTs & 63 & 69 & 79 \\
\hline
\end{tabular}

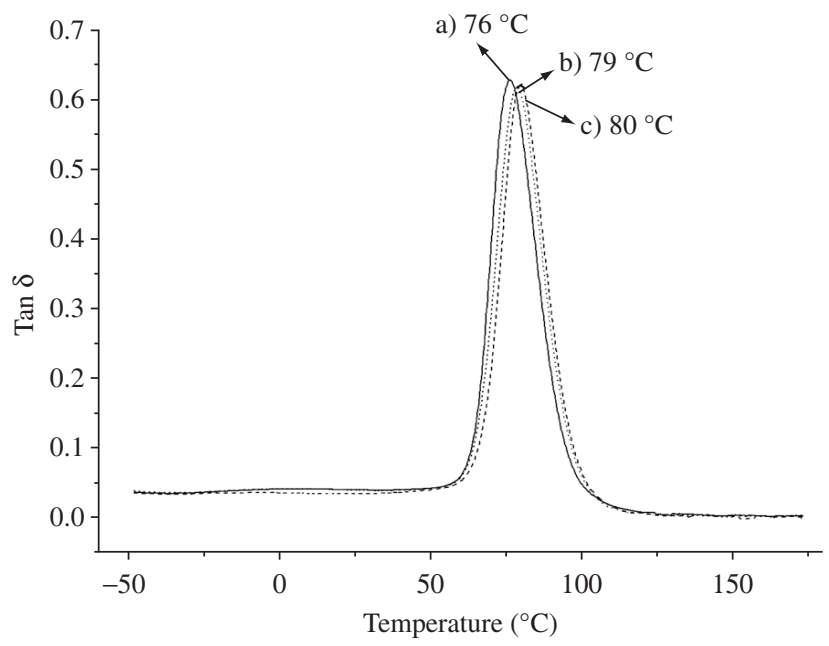

(b)

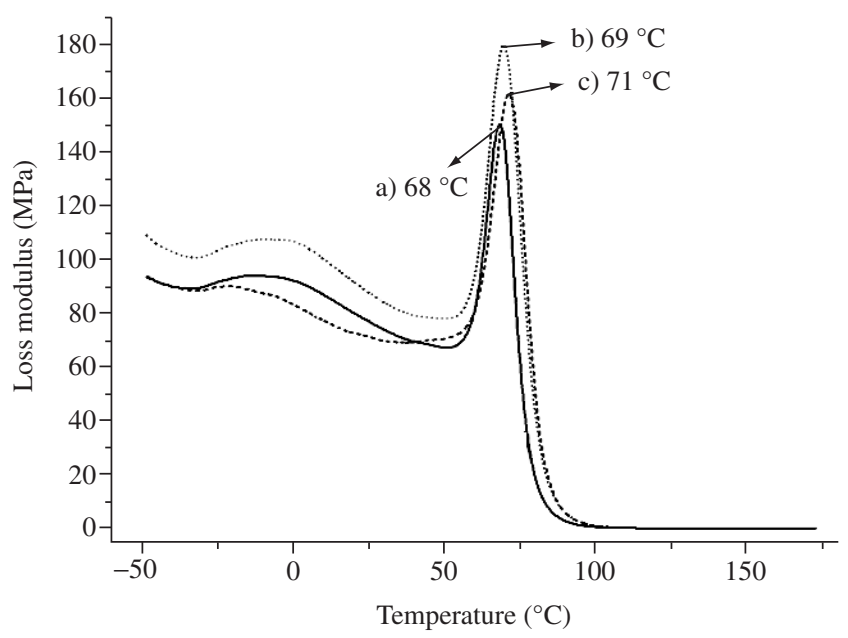

(c)

Figure 7. DMA curves for CNT/epoxy composites: a) Storage modulus vs. T; and b) Tan $\delta$ vs. T; and c) Loss modulus vs. T. 
before and after curing. The viscosity of the resin/acetone/SWCNTs dispersions in epoxy increased, in general, in relation to the neat epoxy. The inclusion of SWCNTs could not be traced by infrared spectroscopy (FTIR) of the uncured resin, although the spectra of the cured dispersions were slightly different from that of the neat cured resin. In the thermogravimetric analysis, some residual solvent was found in the dispersions. This and the presence of SWCNTs itself may have been responsible for reducing cross-link density of the cured nanocomposites.

Tensile tests showed an apparent increase in Young's modulus and strength and the elongation at break remained constant with the addition of SWCNTs. An increasing trend was also found in compression strength and modulus with the addition of SWCNTs, whereas the flexural properties were virtually unaffected by the SWCNTs. These results along with the decrease in Izod impact strength of the samples with SWCNTs appear to be an indication of an inadequate bonding between the phases. Although the changes in properties indicated a general trend, it is important to bear in mind that the mean values of some of the properties of the nanocomposites were within the experimental error of the results for the pure epoxy.

It was noted a significant change in storage modulus of the nanocomposites up to the vicinity of the $\mathrm{T}_{\mathrm{g}}$ of the epoxy, especially with $0.25 \% \mathrm{w} . \mathrm{w}^{-1}$ of SWCNTs. The $\mathrm{T}_{\mathrm{g}}$ of the epoxy was also affected, although slightly, by the addition of SWCNTs. In all, the results indicate that the addition of small amounts of SWCNTs to the epoxy may induce some structural changes in the epoxy matrix which reflect on its viscoelastic properties.

Since stiffness and strength appear to increase with the addition of SWCNTs, this may be an indication that the addition of higher CNT contents could improve more sharply the properties of the final material. In this case, care must be taken to ensure that dispersion is adequate so that a more significant increase in properties may be achieved.

\section{Acknowledgements}

The authors would like to thank CAPES-PROCAD (Project 0303054) for the financial support and for the scholarship to Mr. M. R. Loos. Also, we would like to acknowledge UFMG for the support related to the Raman spectroscopy.

\section{References}

1. Fidelus JD, Wiesel E, Gojny FH, Schulte K, Wagner HD. Thermomechanical properties of randomly oriented carbon/epoxy nanocomposites. Composites A 2005; 36(11):1555-1561.

2. Shen J, Huang W, Wu L, Hu Y, Ye M. The reinforcement role of different amino-functionalized multi-walled carbon nanotubes in epoxy nanocomposites. Composites Science and Technology 2007; 67(15-16):3041-3050.

3. Xu CL, Wei BQ, Ma RZ, Liang J, Ma XK, Wu DH. Fabrication of aluminum-carbon composites and their electrical properties Carbon 1999; 37(5):855-858.

4. Peigney A, Flahaut E, Laurent C, Chastel F, Rousset A. Aligned carbon nanotubes in ceramic-matrix nanocomposites prepared by hightemperature extrusion. Chemical Physics Letters 2002; 352(1-2):20-25.

5. Zhou YX, Pervin F, Lewis L, Jeelani S. Experimental study on the thermal properties of multi-walled carbon nanotube reinforced epoxy. Materials Science and Engineering A 2007; 452:657-664.

6. Dong B, Yang Z, Huang Y, Li HL. Study on tribological properties of multi-walled carbon nanotubes/epoxy resin nanocomposites. Tribology Letters 2005; 20(3-4):251-254.

7. Gong XY, Liu J, Baskaran S, Voise RD, Young JS. Surfactant-assisted processing of carbon nanotube/polymer composites. Chemistry of Materials 2000; 12(4):1049-1052.

8. Puglia D, Valentini L, Armentano I, Kenny JM. Effects of single-walled carbon nanotube incorporation on the cure reaction of epoxy resin and its detection by Raman spectroscopy. Diamond and Related Materials 2003; 12(3-7):827-832.

9. Lau KT, Lu M, Lam CK, Cheung HY, Sheng FL, Li HL. Thermal and mechanical properties of single-walled carbon nanotube bundlereinforced epoxy nanocomposites: The role of solvent for nanotube dispersion. Composites Science and Technology 2005; 65(5):719-725.

10. LiaoYH, Marietta-Tondin O, Liang ZY, Zhang C, Wang B. Investigation of the dispersion process of SWNTs/SC-15 epoxy resin nanocomposites. Materials Science and Engineering A 2004; 385(1-2):175-181.

11. Song YS, Youn JR. Influence of dispersion states of carbon nanotubes on physical properties of epoxy nanocomposites. Carbon 2005; 43(7):1378-1385.

12. Loos MR, Coelho LAF, Pezzin SH, Amico SC. The effect of acetone addition on the properties of epoxy. Polímeros: Ciência e Tecnologia 2008; 18(1):76-80.

13. Qian JW, Miao YM, Zhang L, Chen HL. Influence of viscosity slope coefficient of CA and its blends in dilute solutions on permeation flux of their films for MeOH/MTBE mixture. Journal of Membrane Science 2002; 203(1-2):167-173.

14. Cotiuga I, Picchioni F, Agarwal US, Wouters D, Loos J, Lemstra PJ. Block-copolymer-assisted solubilization of carbon nanotubes and exfoliation monitoring through viscosity. Macromolecular Rapid Communications 2006; 27(13):1073-078.

15. Licea-Jimenez L, Henrio PY, Lund A, Laurie TM, Perez-Garcia AS, Nyborg L, et al. WNT reinforced melamine-formaldehyde containing alpha-cellulose. Composites Science and Technology 2007; 67(5):844-854.

16. Li J, He WD, Yang LP, Sun XL, Hua Q. Preparation of multi-walled carbon nanotubes grafted with synthetic poly(L-lysine) through surface-initiated ring-opening polymerization. Polymer 2007; 48(15):4352-4360.

17. Lau KT, Lu M, Lam CK, Cheung HY, Sheng FL, Li HL. Thermal and mechanical properties of single-walled carbon nanotube bundlereinforced epoxy nanocomposites: the role of solvent for nanotube dispersion. Composites Science and Technology 2005; 65(5):719-725.

18. Hong SG, Wu CS. DSC and FTIR analysis of the curing behaviors of epoxy/DICY/solvent open systems. Thermochimica Acta 1998; 316(2):167-175.

19. Allaoui A, Bai S, Cheng HM, Bai JB. Mechanical and electrical properties of a MWNT/epoxy composite. Composites Science and Technology 2002; 62(15):1993-1998.

20. Loos MR, Coelho LAF, Pezzin SH, Bergmann CP, Amico SC. Efeito da Adição de Nanotubos de Carbono nas Propriedades Mecânicas e Térmicas de Matrizes Epóxi. Proceedings of the Carbono; 2007 Nov. 18-22; Gramado, RS, Brazil; 2007. p. 448-452. (in Portuguese).

21. Ci LJ, Bai JC. The reinforcement role of carbon nanotubes in epoxy composites with different matrix stiffness. Composites Science and Technology 2006; 66(3-4):599-603.

22. Schadler LS, Giannaris SC, Ajayana PM. Load transfer in carbon nanotube epoxy composites. Applied Physics Letters 1998; 73(26):3842-3844.

23. Moniruzzaman M, Du FM, Romero N, Winey KI. Increased flexural modulus and strength in NCPS/epoxy composites by a new fabrication method. Polymer 2006; 47(1):293-298.

24. Lau KT, Shi SQ. Failure mechanisms of carbon nanotube/epoxy composites pretreated in different temperature environments. Carbon 2002; 40(15):2965-2968.

25. Miyagawa H, Drzal LT. Thermo-physical and impact properties of epoxy nanocomposites reinforced by single-wall carbon nanotubes. Polymer 2004; 45(15):5163-5170.

26. Evtushenko YUM, Ivanov VM, Zaitsev BE. Determination of Epoxide and Hydroxyl Groups in Epoxide Resins by IR Spectrometry. Journal of Analytical Chemistry 2003; 58(4):347-50. 